\title{
Understanding desiccation tolerance using the resurrection plant Boea hygrometrica as a model system
}

\author{
Jayeeta Mitra ${ }^{1,2}$, Guanghui X $\mathbf{u}^{1}$, Bo Wang ${ }^{1}$, Meijing Li $^{1}$ and Xin Deng ${ }^{1}$ * \\ ${ }^{1}$ Key Laboratory of Plant Resources, Institute of Botany, Chinese Academy of Sciences, Beijing, China \\ ${ }^{2}$ Department of Life Science and Bioinformatics, Assam University, Silchar, India
}

\section{Edited by:}

Jill Margaret Farrant, University of Cape Town, South Africa

Reviewed by:

Katya Georgieva, Institute of Plant Physiology and Genetics, Bulgaria Dimitar Djilianov, Agrobioinstitute, Bulgaria

\section{${ }^{*}$ Correspondence:}

Xin Deng, Key Laboratory of Plant Resources, Institute of Botany, Chinese Academy of Sciences, Nanxincun 20, Beijing 100093, China e-mail:deng@ibcas.ac.cn

\begin{abstract}
Vegetative tissues of Boea hygrometrica, a member of the Gesneriaceae family, can tolerate severe water loss to desiccated state and fully recover upon rehydration. Unlike many other so called "resurrection plants," the detached leaves of B. hygrometrica also possess the same level of capacity for desiccation tolerance (DT) as that of whole plant. $B$. hygrometrica is distributed widely from the tropics to northern temperate regions in East Asia and grows vigorously in areas around limestone rocks, where dehydration occurs frequently, rapidly, and profoundly. The properties of detached B. hygrometrica leaves and relative ease of culture have made it a useful system to study the adaptive mechanisms of DT. Extensive studies have been conducted to identify the physiological, cellular, and molecular mechanisms underlying DT in the last decade, including specific responses to water stress, such as cell wall folding and pigment-protein complex stabilizing in desiccated leaves. In this review, the insight into the structural, physiological, and biochemical, and molecular alterations that accompany the acquisition of DT in B. hygrometrica is described. Finally a future perspective is proposed, with an emphasis on the emerging regulatory roles of retroelements and histone modifications in the acquisition of DT, and the need of establishment of genome sequence database and high throughput techniques to identify novel regulators for fully understanding of the matrix of DT.
\end{abstract}

Keywords: Boea hygrometrica, desiccation tolerance, gene expression regulation, resurrection plant, adaptation

\section{INTRODUCTION}

The productivity and distribution of plants are affected to a large extent by environmental conditions, due to the immobile nature of plants. A major environmental stress experienced by plants occurs during periods of water limitation, i.e., drought. Drought stress differs according to the availability of water and ranges from stochastic periods of mild water deficit to extreme water loss (desiccation). Most plants can withstand drought for a short period, via physiological and morphological changes such as stomatal closure and architecture specialization to reduce water loss and modulate water uptake, but will experience extensive cellular damage from which recovery is not possible when water content falls below 40\% relative water content (RWC; Höfler et al., 1941). Only a group of plants called resurrection plants have desiccation tolerance (DT), e.g., the ability to withstand cellular water loss to $90 \%$ RWC and above (Dinakar et al., 2012; Gechev et al., 2012). These plants assume a dormant state whereby they can withstand prolonged periods of drought and resume active metabolism when water become available again. Mechanical damage, destabilization, or loss of membrane integrity, and oxidative stress related to disruption of metabolism are the major challenge for plants to survive cellular desiccation (Vicré et al., 2004a; Farrant et al., 2007). Unlike bryophytes and lichens, which can withstand rapid dehydration by the mechanism of rehydration-induced repair process, resurrection angiosperms employ more complex DT pathways that require both short and long term genetic and biochemical reactions (Farrant et al., 2009).
Desiccation tolerance is found commonly in lower plants such as lichens and bryophytes, and are absent in gymnosperms and are found rarely in pteridophytes and angiosperms (Farrant et al., 2007; Porembski, 2011). So far, about 1,300 desiccationtolerant plants have been described, out of which only 135 species are angiosperms, which are scattered among 13 largely unrelated families (Gaff and Oliver, 2013). Among the dicotyledoneae, the Gesneriaceae contains a variety of resurrection plants. However, DT ability was reported only for several genera including Boea, Ramonda, Paraboea, and Haberlea (Müller et al., 1997; Jiang et al., 2007; Huang et al., 2012). In the two families containing the largest number of monocotyledoneae genera of desiccation-tolerant species, the desiccation-tolerant species make up only a small proportion of their genus and these genera only a small fraction of the family (Gaff and Oliver, 2013). This phenomenon suggests that DT has evolved independently from desiccation-sensitive progenitors (Oliver et al., 2000; Gaff and Oliver, 2013). Thus the DT-associated responses and the underlying mechanisms in angiosperm resurrection plants are likely diversified; some are common, while the others are species-dependent.

Gesneriaceae family contains many resurrection species. For example, Boea hygrometrica and Paraboea rufescens, that are native to the Southeast Asia, and Haberlea rhodopensis, Ramonda myconi, and Ramonda serbica, that distribute mainly in the Balkan Peninsula. This review will focus on the simplified research system of DT in B. hygrometrica, structural, physiological, and biochemical, 
and molecular alterations that accompany the acquisition of DT in B. hygrometrica. The specificity of the DT of B. hygrometrica will be discussed in comparison with the other resurrection species belonging to the same family that have habitats where drought is only one of the main stresses.

\section{A SIMPLIFIED MODEL SYSTEM TO STUDY DT USING B. hyhgrometrica DETACHED LEAVES}

Boea hygrometrica is a small, perennial, and herbaceous plant belonging to the Gesneriaceae family. The species is distributed widely from the tropics to northern temperate regions in East Asia and grows vigorously in limestone rocks, where the soil is alkaline and calcium-rich, and dehydration occurs frequently, rapidly, and profoundly. B. hygrometrica plants are desiccated and shrink with a withered appearance in dry weather, and become hydrated again after rain in the native habitat (Figure 1). B. hygrometrica can be cultivated easily under greenhouse conditions. Seed sets with the aid of manual pollination. The seeds of B. hygrometrica are similar in size to Arabidopsis thaliana and the number of seeds in one capsule typically exceeds a hundred. The DT ability and ease of handling and maintenance has made B. hygrometrica a suitable model system to investigate molecular mechanism of DT.

A remarkable ability of $B$. hygrometrica is that a single detached leaf or leaf disc also possesses the same level of capacity for DT as that of whole plant, which was found only in a sub set of the resurrection plants such as Craterostigma plantagineum, Myrothamnus flabellifolia, and Craterostigma nanum (Gaff and Loveys, 1984; Bartels et al., 1990; Sherwin, 1995; Jiang et al., 2007). The detached leaves are useful to investigate DT, taking the advantage that these leaves are not affected by interference from developmental regulation and long-distance signaling from other organs during dehydration and rehydration (Jiang et al., 2007). To date, studies using this system have been conducted to characterize the architectural, physiological, cellular, and molecular mechanisms of the
DT of B. hygrometrica, revealing dehydration responses such as cell wall folding, accumulation of raffinose oligosaccharides, late embryogenesis abundant (LEA) proteins and small heat shock proteins (sHSPs), antioxidative agents, and enzymes and stabilization of photosynthetic protein-pigment complexes (Jiang et al., 2007; Liu et al., 2009; Wang et al., 2009a; Zhang et al., 2013).

Boea hygrometrica survives rapid desiccation by air-drying; however, this ability is limited to natural habitats where water is periodically available. B. hygrometrica plants grown under well-irrigated conditions in greenhouse conditions are unable to tolerate rapid desiccation, unless pretreated with a dehydration/rehydration cycle, indicating that the slow soil drought and re-irrigation procedure is critical. The non-acclimated and acclimated plants lose water at similar rate although non-acclimated plants fail to revive after rehydration, while acclimated plants resurrect after rehydration. This characteristic has not been reported for other DT plants, yet the observation that acclimation improves drought, cold and heat tolerance had been reported in many plant species (Bayley et al., 2001; Holmstrup et al., 2002). A common view is that a period of acclimation activates stress-induced gene expression and metabolic changes which in turn are beneficial to plant survival under stress (Ahamed et al., 2012).

\section{THE BIOLOGICAL CHARACTERS AND STRUCTURAL ADAPTATION OF B. hygrometrica IN RESPONSE TO DEHYDRATION \\ LEAF CURLING AND CELL WALL FOLDING DURING DEHYDRATION}

Adaptive changes in leaf architecture are observed in response to periods of water deficit. These alterations are generally slower responses. For example, dehydration results in leaf shrinkage and curling toward the adaxial surface in many resurrection plants, so that the epidermis hairs on abaxial surface result in a graygreen coloration. The curling of the leaf surface and crowded epidermis hairs on the abaxial surface is considered a protective strategy against photoinhibition and reactive oxygen species
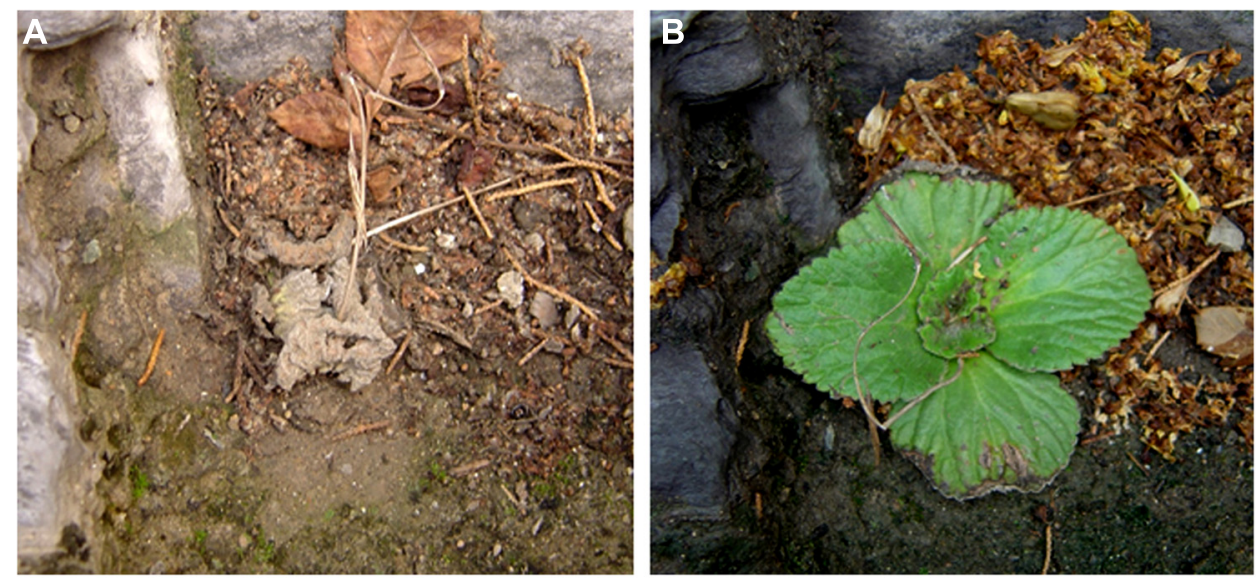

FIGURE 1 | A plant of $\boldsymbol{B}$. hygrometrica at desiccated and hydrated stages. B. hygrometrica plant is desiccated and shrink with a withered appearance in dry weather (A), but become hydrated again after rain $(\mathbf{B})$ in the native habitat. Photographs were taken for the same plant in Beijing Botanic Garden by Dr. Haihong Shang 
(ROS) production by reducing absorption of radiation, which is followed by the accumulation of anthyocyanins and other phenolic compounds which protect against solar radiation (Farrant and Moore, 2011). This process is reversible after rehydration and related to cell wall folding. The progressive loss of water creates a tremendous amount of stress on the architecture of the plant cell, which in turn causes changes in plant cell wall polysaccharides and proteins (Jones and McQueen-Mason, 2004; Vicré et al., 2004a; Farrant et al., 2007; Moore et al., 2008; Wang et al., 2009a). The cell wall remains flexible during dehydration and becomes highly folded, which is helpful to reduce the extent of plasmolysis (Jones and McQueen-Mason, 2004; Vicré et al., 2004b; Moore et al., 2008). By cell wall folding, what is more, damage to the plasma membrane is minimized and the integrity of cell structures and the cell-to-cell communication through plasmodesmata is maintained (Neale et al., 2000; Jones and McQueen-Mason, 2004). The unbalanced folding of cell walls and shrinkage of cells in turn enables leaf curling and reversible folding (Moore et al., 2006, 2008; Farrant et al., 2007). Another process by which the plants can mitigate mechanical stress is by increased vacuolation wherein the water in vacuoles is replaced by non-aqueous substances (Oliver et al., 2011).

In B. hygrometrica, the contents of cell wall associated proteins and lignin were reduced in desiccated leaves (Wang et al., 2009a; Wu et al., 2009). In agreement, a gene (BhGRP1) encoding a cell wall structural glycine-rich protein (GRP), was isolated from the cDNA library of B. hygrometrica leaves dehydrated for $2 \mathrm{~h}$ with the help of cDNA microarray approach. GRPs form a large family of heterogenous proteins that contains $60-70 \%$ of glycine residues out of the total amount of amino acid residues (Sachetto-Martins et al., 2000). There are two types of GRPs in plants. One contains an RNA-binding domain and is thought to be involved in regulation of RNA processing inside the nucleus or function similarly as that to animal cytokeratin (Mousavi and Hotta, 2005). The other class of GRPs is thought to be present in the extracellular matrix to form the structural components of plant cell walls (Sachetto-Martins et al., 2000). These GRPs are influenced by external agencies such as water, ozone stress, hormone treatment, wounding, low temperature, etc. It has also been found that water stress results in the induction of several GRP genes in both resurrection and non-resurrection plants (de Oliveira et al., 1990; Neale et al., 2000). Besides, a gene encoding a peptide highly homologous to dirigent proteins and a gene encoding germin-like proteins were identified among the dehydrationinduced EST (Wang et al., 2009a; Wu et al., 2009). These proteins likely function in lignin synthesis and cell wall redox status, respectively, in turn playing a role in cell wall composition and flexibility.

\section{ROOT-SHOOT COMMUNICATION DURING DEHYDRATION}

In the monocot resurrection plant Sporobolus stapfianus, evidence have shown that a root signal/s may be important for DT, according to the observation that disturbance of the root system during the drying period can disrupt the acquisition of the desiccationtolerant state (Gaff et al., 1997). In contrast, it is unlikely that a signal from the root system is necessary for DT in aerial organs, given that the detached leaves of $B$. hygrometrica possesses the same capacity for DT as that of the whole plant. The tap root system of B. hygrometrica is short and weak, counting for only a small proportion of the overall biomass. However, when dehydrated as a whole plant, the roots of B. hygrometrica become desiccated at similar rate and exhibit similar DT ability as leaves, implying that the root system of $B$. hygrometrica maintains a congruent response to dehydration with leaves, although the signal transduction pathway is unknown for shoot-root communication.

\section{GROWTH REGULATION DURING DEHYDRATION}

Boea hygrometrica plants cease growth soon after dehydration to reach a quiescent state. A heat shock factor from B. hygrometrica, BhHSF1, had been identified that may play a role in growth regulation in response to water limited conditions (Zhu et al., 2009). BhHSF1 expression conferred plant stress tolerance and led to organ growth retardation, which correlated with positive regulation of drought-induced genes such as LEAs, HSPs, and GOLS, and negatively regulating cell division-related genes including CDC45 and MCM10. Thus this factor is possibly involved in the transduction of drought signal to growth regulation, attributing to rapid acquisition of DT, and growth cessation in B. hygrometrica. The synergistic regulation of drought stress genes and cell cycle genes by a common transcription factor is regarded as a mechanism to integrate environmental and developmental signals and thus reprogram gene expression to ensure plant survival at the expense of growth retardation.

\section{PHYSIOLOGICAL AND BIOCHEMICAL PROTECTION MECHANISMS IN B. hygrometrica IN RESPONSE TO CELLULAR DEHYDRATION}

Extensive studies have revealed several important aspects on physiological and biochemical levels that are beneficial to resurrection plant for survival under desiccation stress, for example, the control of ROS levels, the regulation of photosynthesis, and carbohydrates metabolism. Metabolic profiling of several DT plants has revealed alterations of small molecules during desiccation, such as amino acids and sugars (Oliver et al., 2011). For B. hygrometrica, the maintenance of photosynthetic apparatus and the protective molecules are of particular interest and discussed in the next section.

\section{PROTECTION OF PHOTOSYNTHETIC APPARATUS DURING DEHYDRATION}

Photosynthesis is highly sensitive to the periods of water deficit. Impairment of photosynthesis, especially the leakage of electrons to $\mathrm{O}_{2}$ and photorespiration, results in oxidative burst in chloroplasts (Cruz de Carvalho, 2008). Photosynthesis is completely inhibited when water deficiency progresses in many resurrection plants, including $B$. hygrometrica, but in contrast to non-resurrection plants, the process is reestablished soon after rehydration (Bartels and Hussain, 2011; Porembski, 2011; Dinakar et al., 2012). The mechanism underlying photosynthesis changes is not fully understood, however the following observations have been observed in B. hygrometrica: (1) being homoiochlorophyllous, it retains chlorophyll contents during desiccation (Deng etal., 2003); (2) chloroplasts assume an irregular shape soon after dehydration, but the thylakoid structure remains visible 
under electronic microscope (Wang et al., 2009a); (3) thylakoid pigment-protein complexes are well conserved throughout the process of desiccation and rehydration in B. hygrometrica (Deng et al., 2003). The remaining of chlorophyll, thylakoid structure, and photosystem complexes contributes to rapid recovery of photosynthesis upon rehydration, but additional mechanisms will be necessary to stabilize these macromolecules and to minimize ROS accumulation, thereby protecting the plant from further damage (Farrant and Moore, 2011). In B. hygrometrica the carotenoid content is found increased during dehydration (Deng et al., 2003). Carotenoids play a protective role against photoinhibition. As important components of carotenoids, xanthophyll cycle pigments, are active antioxidants in chloroplast and the precursors of stress hormone abscisic acid ( $\mathrm{ABA}$; Georgieva et al., 2009). Furthermore, two dehydration-induced chloroplast-localized LEA proteins were found to confer drought tolerance via stabilizing photosynthesis related proteins when ectopically expressed in tobacco (Liu et al., 2009). Accordingly, carotenoids and LEA proteins are implicated to play a role in this process.

\section{THE ACCUMULATION OF PROTECTIVE MOLECULES IN RESPONSE TO DEHYDRATION}

Antioxidant enzymes, osmolytes, and protective macromolecules accumulate to high levels in dehydrated DT plants. The accumulation of these molecules prevents accumulation of ROS, and protects membranes and proteins by forming a glass state, which reduces the metabolic rate (Oliver et al., 2000; Phillips et al., 2002; Bartels and Hussain, 2011).

\section{Sugars}

One of the principal osmolytes that accumulates during desiccation in DT plants, including the two European Gesneriaceae genera, Ramonda spp. and Haberlea spp., is sucrose (Ingram and Bartels, 1996; Norwood et al., 2000; Martinelli, 2008). Sucrose acts as an osmoprotectant to stabilize the structure of macromolecules to protect biological membranes (Martinelli, 2008), and may function as a signaling component to regulate carbohydrate status, growth, and energy metabolism. Besides, oligosaccharides such as raffinose and trehalose accumulate in many angiosperms during desiccation and play a prominent role by replacement and vitrification, thereby conferring cellular protection (Norwood etal., 2000; Farrant etal., 2007). Raffinose may also prevent crystallization of sucrose during drying (Müller et al., 1997). Raffinose synthesized from galactinol and sucrose by raffinose synthase protects against paraquat induced oxidative damage (Nishizawa et al., 2008). Carbohydrate reserves such as starch become the accumulate at the onset principle source for production of sucrose during prolonged dehydration when photosynthesis is suspended (Norwood et al., 2000). Another alternative source of carbon for sucrose synthesis is stachyose (Norwood et al., 2003).

In $B$. hygrometrica, dehydration-inducible genes encoding galactinol synthase and raffinose synthase have been identified (Wang etal., 2009b). The transgenic plants overexpressing BhGoLS1 improved drought tolerance (Wang etal., 2009b). It is interesting that galactinol accumulate in B. hygrometrica was similar to B. hygroscopica and Xerophyta viscosa, but different from that in Arabidopsis. Galactinol increased to the highest levels soon after the onset of dehydration, and remain at basal levels in desiccated leaves of the resurrection species; but accumulated gradually to high levels after 14 days of water stress in Arabidopsis (Albini et al., 1999; Peters et al., 2007; Wang et al., 2012). These observations imply that the accumulation of galactinol and raffinose may not contribute to the osmotic protection in fully desiccated leaves in at least the above-mentioned resurrection species. Hereby, the function of galactinol in DT will need further investigation.

In addition, raffinose also accumulates soon after dehydration in B. hygrometrica. To the contrary, raffinose (and sucrose) accumulated only when leaf RWC decreases to $25 \%$ or lower in $H$. rhodopensis (Djilianov et al., 2011). It was proposed that the initial high sucrose and raffinose concentration in H. rhodopensis, as revealed by the comparison with its non-DT relative Chirita eberhardtii, might be important for establishing the resurrection phenotype in this species (Djilianov et al., 2011). Therefore it appears that although the dynamics of raffinose accumulation may vary in individual species, the high level of raffinose in the early stage of dehydration is common to B. hygrometrica and $H$. rhodopensis, and the maintaining constant high levels of sucrose and raffinose might be a specific adaptation to be able to survive a very rapid dehydration in these species.

\section{Protective proteins}

In $B$. hygrometrica it was inferred that mechanisms exist which prevent protein aggregation and degradation (Jiang et al., 2007). Two major classes of protective proteins are sHSPs and LEA proteins, which constitute the largest group of hydrophillins in plants (Ingram and Bartels, 1996; Battaglia et al., 2008). The hydrophillins are predicted to protect proteins and macromolecules from dehydration by creating a water hydration "shell" (Oliver et al., 2011). LEA proteins were first discovered during the final stages of seed development (Dure and Chalan, 1981). Further studies have shown that LEA proteins accumulate in response to drought, freezing, salt stress, and by treatment with the phytohormone ABA (Shao et al., 2005; Tunnacliffe and Wise, 2007). Studies also revealed that LEA proteins are produced in vegetative tissues and seeds both in desiccation-sensitive and tolerant plants during drought (Piatkowski etal., 1990; Battaglia et al., 2008; Hundertmark and Hincha, 2008). Increased drought tolerance has been found in transgenic plants such as barley, Tamarix androssowii and Brassica napus which overexpress LEA genes (Xu et al., 1996; Babu etal., 2004; Park etal., 2005). LEA proteins help to minimize damages caused due to stress by functioning in the protection of membranes and proteins, and alleviate the increase in ion concentration (Ingram and Bartels, 1996; Shao et al., 2005; Tunnacliffe and Wise, 2007). In the desiccated state, LEA proteins along with sugars form a "glassy" state (Buitink and Leprince, 2004). Based on amino acid sequence homology and specific structural features LEA proteins were classified into five groups (Dure et al., 1989). So far, only two genes encoding group 4 LEA proteins had been cloned from $B$. hygrometrica. Overexpression of both BhLEA1 and BhLEA2 improved transgenic tobacco drought tolerance as evidenced by increased photosynthetic efficiency and membrane integrity, increased abundance of 
ROS scavenging enzymes such as superoxide dismutase (SOD) and proxidase (POD; Liu et al., 2009). Furthermore, chloroplastic membrane-bound proteins such as PsBO and LHCII were highly stable in drought-stressed BhLEA1 transgenic plants, and chloroplastic stroma proteins RbcL were better conserved in droughtstressed BhLEA2 transgenic plants, highlighting the important roles of LEA proteins in the protection of photosynthetic proteins (Liu et al., 2009).

Similarly, sHSPs protect proteins from both aggregation and dehydration by acting as molecular chaperones (Garrido et al., 2012). Ten genes encoding sHSPs were cloned from B. hygrometrica, among which, six cytosol-targeted sHSP coding genes were induced after desiccation and tended to remain highly abundant during rehydration (Zhang et al., 2013). It has been established that stress conditions affect cellular environment at least in part by disturbing protein folding. There are two processes to eliminate unfolded and misfolded proteins in the cells, one in the endoplasmic reticulum associated degradation (ERAD) and the other cytoplasm protein response (CPR; Mishiba et al., 2013). The finding of dehydration-inducible cytosol sHSPs coding genes indicated a role of sHSPs in the stabilization of cytosolic proteins.

\section{Antioxidants and ROS scavenging enzymes}

A large number of stressful conditions such as salinity, drought, highlight, toxicity, pathogens cause extra ROS (Mittler et al., 2011). The complex antioxidative defense system of plants consists of non-enzymatic and enzymatic components. Recent studies indicate that these components exist in different organelles such as chloroplasts, mitochondria, and peroxisomes (Pang and Wang, 2008). Non-enzymatic components include the major cellular redox buffers ascorbate (AsA) and glutathione (GSH) as well as tocopherol (vitamin E), carotenoids, and phenolic compounds (Mittler, 2002). Interacting with numerous cellular components, these antioxidants modulate processes from mitosis and cell elongation to senescence and cell death (De Pinto and De Gara, 2004). (Poly)-phenols together with flavonoids appear to be particularly important in resurrection plants acting as "sun screen" pigments to shade the desiccated photosynthetic apparatus, and which will help to avoid ${ }^{1} \mathrm{O}_{2}$ formation (Farrant et al., 2003; Kranner and Birtic, 2005). In R. serbica, the content of phenolic acids is found to be unusually large in comparison with other plants (Booker and Miller, 1998; Sgherri et al., 2004). The enzymatic components comprise of several antioxidant enzymes such as SOD, catalase (CAT), guaiacol peroxidase (GPX), ascorbate peroxidase (APX), monodehydro ascorbate reductase (MDHAR), dehydroascorbate reductase (DHAR), and glutathione reductase (GR; Noctor and Foyer, 1998). These enzymes operate in different subcellular compartments and respond in concert when cells are exposed to oxidative stress. In Craterostigma wilmsii and $X . v i s c o s a$, vegetative tissues show increased expression of enzymatic antioxidants genes such as APX, GR, and SOD during drying or rehydration (Ingram and Bartels, 1996; Sherwin and Farrant, 1998). Mowla et al. (2002) identified a novel stressinducible antioxidant enzyme XvPer1 from the resurrection plant $X$. viscosa, which may function to protect nucleic acids within the nucleus against oxidative injury. In B. hygrometrica, a protein annotated to polyphenol oxidase precursor was identified to be induced by dehydration, along with the proteins annotated to glutathione peromidase and glutathione $S$-transferase (Jiang et al., 2007). In consistence, the content of antioxidants GSH and the activity of ROS scavenging enzyme polyphenol oxidase are increased in B. hygrometrica during desiccation (Jiang et al., 2007). Polyphenol activity was also found higher in desiccated leaves in R. serbica and H. rhodopensis (Jovanovic et al., 2011). In a recent study it was found out that polyphenols protect chloroplast membranes during plant desiccation and recovery by helping the membrane to mitigate oxidation damage and facilitate in starting the photosynthesis when the plant recovers (Georgieva et al., 2010).

\section{EVALUATION OF THE MOLECULAR MECHANISMS OF DT IN B. hygrometrica}

The molecular mechanisms of DT in resurrection plants have been investigated since the 1990s (Bartels et al., 1990). Numerous dehydration-inducible genes have been cloned from resurrection plants as summarized by a series of reviews (Ingram and Bartels, 1996; Farrant et al., 2007; Farrant and Moore, 2011; Gechev et al., 2012; Gaff and Oliver, 2013). The advances of "omics" technologies have greatly facilitate the discovery of DT-related genes and the understanding of the molecular mechanisms of DT. Since the last century, technologies of mRNA differential display, proteomic, macroarray hybridization have been applied to study the DT mechanism in B. hygrometrica, which led to the discovery of many dehydration-induced genes and proteins (Deng et al., 1999; Jiang et al., 2007; Wang et al., 2009a).

Molecular studies based on these finding have revealed a general regulation module that transcription factors control the dehydration-induced expression of functional genes downstream of phytohormone-dependent and -independent signal transduction. Plants respond immediately to water stress by various kinds of physiological responses including a rapid increase in $\mathrm{ABA}$ concentration. Both ABA-dependent and -independent signal pathways have been revealed in the activation of gene expression. The genes encoding the protective proteins such as aldehyde dehydrogenase, heat shock factors and LEA proteins are thought to be regulated by ABA-directed signal pathways (Kirch et al., 2001; Deng et al., 2006; Wu et al., 2011). Dehydration-triggered gene expression is regulated by a cascade of signaling molecules such as transcription factors, calmodulins, and kinases and phosphatases. One example of hormonal signaling in B. hygrometrica is ABA-dependent synthesis of galactinol and raffinose family oligosaccharide (RFOs). Both BhGoLS1 and BhRFS were induced by ABA (Wang et al., 2009b; Wang etal., 2012). The activation of BhGoLS1 was achieved by the regulation of a dehydration and ABA-inducible WRKY transcription factor which binds to the $W$ box elements in the promoter region of BhGoLS1 (Wang et al., 2009b).

The role of other phytohormones in DT regulation in B. hygrometrica has not be investigated so far, however, the study in $H$. rhodopensis, another DT species in Gesneriaceae, had revealed the active participation of jasmonic acid, salicylic acid, cytokinins, and auxins in the dehydration response (Djilianov et al., 2013). As proposed by the authors, DT appears to be strongly influenced by the earliest and very high accumulation of JA and ABA, 
which coincides with the accumulation of early up-regulated transcripts, and the steady high levels of SA during the whole process of desiccation (Georgieva et al., 2012; Djilianov et al., 2013). A forthcoming study on the hormone changes during dehydration and rehydration in B. hygrometrica will shed light on the specificity and universality in the hormone regulation of DT molecular events among species in Gesneriaceae.

Abscisic acid and calcium have been shown to interact in regulation of dehydration-induced gene expression in B. hygrometrica. Calcium regulates expression of a dehydration-inducible gene BhC2DP1 in B. hygrometrica (Zhang et al., 2012). BhC2DP1 encodes a small protein with a single $\mathrm{C} 2$ domain protein, which is capable of binding $\mathrm{Ca}^{2+}$. Constitutive expression of BhC2DP1 in Arabidopsis resulted in an ABA-hypersensitive phenotype, which could be rescued by supplementing $\mathrm{Ca}^{2+}$-chelating agent EGTA to growth media. Thus we propose that $\mathrm{Ca}^{2+}$ is necessary for the function of BhC2DP1 in response to ABA. Consistent with this hypothesis BhC2DP1 transcripts accumulate soon after dehydration and exposure to exogenous $\mathrm{Ca}^{2+}$. BhC2DP1 transcription was suppressed by ABA and EGTA, however, was promoted when ABA and EGTA were simultaneously applied. This observation suggests that the transcriptional regulation of $B h C 2 D P 1$ by $A B A$ is $\mathrm{Ca}^{2+}$ dependent. Fine-tuning of BhC2DP1 expression in response to drought highlights the role of exogenous calcium in the DT response.

Calcium is an essential plant macronutrient with key structural and signaling roles and it is rich in the limestone-based alkaline soil (Ji et al., 2009). Excessive $\mathrm{Ca}^{2+}$ in the rhizosphere may also cause soil alkalization and $\mathrm{Ca}^{2+}$ toxicity by preventing the germination of seeds, reducing plant growth rate and formation of tiny yellowish or gold spots in the cell walls of fruits (White and Broadley, 2003; Song et al., 2011). Interestingly, many species in Gesneriaceae family favor calcareous massifs, including both the desiccation-tolerant B. hygrometrica, R. myconi, R. serbica, $P$. rufescens, $H$. rhodopensis, and the desiccation intolerant species of Chirita spp. and Monophyllaea spp. (Picó and Riba, 2002; Sgherri et al., 2004; Georgieva et al., 2008; Kiew, 2009; Huang et al., 2012). The high occurrence of DT species and calciphytes in Gesneriaceae suggests a possible link between environmental calcium and DT. However, does calcium indeed involve in the regulation of DT mechanisms, how these plants limit high calcium damage, how they balances the calcium signal from high calcium stress and dehydration stress, and if the high calcium environment benefits the evolution of DT in the resurrection species of Gesneriaceae are open to question.

Likewise, dehydration of resurrection plants in their natural habitats frequently occurs in combination of different abiotic stresses, each with the potential to exacerbate the damage caused by the others. This is particularly true in the case of Gesnericear resurrection plants that have habitats where drought is not the only main problem. For example, $H$. rhodopensis plants grow in shady rock crevices on limestone at altitudes of 100-1,700 $\mathrm{m}$ in the central to north part in Balkan Mountains and the South in Rhodope Mountains, Ramonda serbica inhabits the shallow organo-mineral soil ( $\mathrm{pH}$ 7.7) that develops in crevices on northern-facing carbonate rocks in the gorges in the Balkan Peninsula, and B. hygrometrica is native of vast area from Northern China to Southeast Asia (Jiang et al., 2007; Rakić et al., 2009; Daskalova et al., 2011; Petrova et al., 2013), growing also on limestone at altitudes of 200-1320 m. In these places, the high temperature and high irradiance in summer will increase the rate of water loss and the low temperature beneath $0^{\circ} \mathrm{C}$ in winter could cause freezing. It has been revealed that the effects of dehydration on photochemical activity of PSII and PSI and photosynthetic oxygen evolution was stronger when desiccation was carried out at high temperature $\left(38^{\circ} \mathrm{C}\right)$ or becomes irreversible damaged during desiccation at high light intensities (350 $\mu \mathrm{mol} \mathrm{m}^{-2} \mathrm{~s}^{-1}$; Georgieva et al., 2008, 2010; Mihailova et al., 2011). However, at least the populations in the northern temperate zone are able to tolerate several cycles of desiccation and rehydration under high temperature and intensive irradiation conditions in summer, and to survive the freezing temperature in winter after gradually dehydrated to an "anhydrobiosis" (quiescent and desiccated) stage during autumn. The similarity of the habitats of these Gesneriaceae resurrection plants highlights the specificity of the DT mechanisms of these plants. Studies on genetic model plants have shown that there are multiple stress perception and signaling pathways, some of which are specific, but others may cross-talk at various steps. It has been established that cold acclimation increases plant freezing tolerance via $C B F$ regulatory hub and overexpressing CBF3/DREB1a, and consequently the CBF regulon, are not only more freezing tolerant than control plants, but are also more tolerant of dehydration stress caused by either drought or high salinity (Kasuga et al., 1999; Thomashow, 2010). Influx of calcium is an important second messenger involved in activating the cold acclimation response (Doherty et al., 2009). Whether low temperature and rhizosphere calcium and alkalization have an impact on the regulation of DT mechanisms in B. hygrometrica and others will help to elucidate the scientific mechanisms behind the adaptive evolution and the DT acquisition of resurrection plants in Gesneriaceae.

\section{CONCLUSIONS AND FUTURE PERSPECTIVES}

As reviewed above, the characterization of $B$. hygrometrica demonstrates that a number of effective, protective mechanisms are induced upon dehydration. A growing body of evidence has suggested that the adaptation of resurrection plants to dry environments is due to novel regulation of existing genes. Changes in gene expression result in morphological and physiological adaptations which enable survival in a desiccated state. In additional to the general regulation module of dehydration-induced gene expression on transcriptional level, there are two novel aspects that probably worth of noticing for DT-associated genetic regulation.

One of the newly recognized regulators in DT is retroelement. The role of retroelement in DT has been illustrated in the case of CDT-1 from the resurrection species C. plantagineum. A series of studies have shown that the dehydration-related ABA-inducible retroelement gene CDT-1 could direct the synthesis of a doublestranded 21 bp short interfering RNA (siRNA), which opened the metabolic pathway for DT through activation of stress-responsive genes (Furini et al., 1997; Smith-Espinoza et al., 2005; Hilbricht et al., 2008). As a major type of transposons, retroelements may silence or alter expression of genes adjacent to insertion sites and generate newly acquired exons (exapted) via transposition, 
contribute to chromosomal rearrangements via recombination, epigenetically alter regional methylation patterns, and provide template sequences for RNA interference (Boyko and Kovalchuk, 2011; Mirouze and Paszkowski, 2011; Gutzat and Scheid, 2012). The transcriptional activation from the transposons may also trigger locus-specific siRNA mediated RNA-directed DNA methylation (Hilbricht et al., 2008; Rigal and Mathieu, 2011; Zhang and Zhu, 2011). Transposon elements can rapidly differentiate genomes within and between species has been illustrated (Piegu et al., 2006; Venner et al., 2009; He etal., 2012). A biological diversity investigation on the patterns of genetic structure of $R$. myconi populations in eight mountain regions has revealed high genetic differentiation between geographical regions (20\%) and among populations within regions (9\%; Dubreuil et al., 2008). To investigate the DT-associated retrotransposon elements from $B$. hygrometrica and other resurrection species will bring interesting insights into the evolution of Gesneriaceae, species differentiation, and the acquisition and regulation of DT ability in this family.

The other type of the possible novel regulators in DT may be represented in chromatin modification. Particularly, recent studies have linked histone modification with drought tolerance (Bruce etal., 2007; Kim et al., 2010). There are at least eight distinct types of modifications found on histones including the well-informed acetylation, methylation, and phosphorylation (Kouzarides, 2007). The increase of H3K4 trimethylation and H3K9 acetylation in Arabidopsis is associated with drought induced expression of stress response genes (Chinnusamy and Zhu, 2009). Recent research shows that H3K4me3 modification mediate the rapid induction of trainable genes in the second round of dehydration, which is a sign of stress memory in plants (Ding et al., 2012). Besides, histone modification may also display a transient up or down regulation during stress response that can also affect target gene expression (Sokol et al., 2007). Transient chromatin modifications mediate acclimation response and heritable chromatin modifications provide within-generation and trans-generational stress memory (Kouzarides, 2007). Because B. hygrometrica has to undergo a drought acclimation before it gains the DT ability, it may be similar with Arabidopsis which keeps a drought memory that brings it a more effective desiccation response. It is possible that the level of a single type of histone modification or even a combined pattern is altered and kept in B. hygrometrica during drought acclimation, which results in the activation of a cascade of downstream genes. Further study on the transient or long term chromatin modifications that regulate gene expression for acquisition of DT will expand the regulation frame of gene expression in resurrection plants.

Definitively, mechanisms of DT could be dissected further with the availability of a genetic system that enables gain and loss of function experiments. Currently the application of genetic approaches is limited by the inability to transform B. hygrometrica and the lack of genome sequence information of this species. Zhang et al. (2011) have analyzed in a systematic way representative chloroplast and mitochondrial genomes of $B$. hygrometrica and the results provide information for a better understanding of organellar genome evolution and function. Nuclear genome sequencing of $B$. hygrometrica is undergoing. Meanwhile, transformations of large genomic DNA fragments from resurrection plant as the donor to Arabidopsis via transformation-competent binary bacterial artificial chromosome (BIBAC) vectors have been employed as a genetic tool for genome-wide screening of functional genes, gene clusters, quantitative trait loci (QTL), transposable elements, chromatin modifications, and other genomic elements. These efforts will help to extend our understanding on the mechanisms of DT acquisition and subsequently facilitate the improvement of drought tolerance of crops and other plants with economic or ecological importance, which is highly desired in the background of global warming.

\section{ACKNOWLEDGMENTS}

We thank Dr. Jonathan Phillips for help with English edition of the manuscript and for constructive discussions. We would also like to thank the following for funding support: the National Natural Science Foundation of China (31270312), the National High Technology Research and Development Program of China (863 Program, 2007AA021403), and the National Basic Research Program of China (973 Program, 2012CB114302) and also convey our gratitude to CAS and TWAS for their help and support.

\section{REFERENCES}

Ahamed, A., Murai-Hatano, M., Ishikawa-Sakurai, J., Hayashi, H., Kawamura, Y., and Uemura, M. (2012). Cold stress-induced acclimation in rice is mediated by root-specific aquaporins. Plant Cell Physiol. 53, 1445-1456. doi: $10.1093 / \mathrm{pcp} / \mathrm{pcs} 089$

Albini, F. M., Murelli, C., Finzi, P. V., Ferrarotti, M., Cantoni, B., Puliga, S., et al. (1999). Galactinol in the leaves of the resurrection plant Boea hygroscopica. Phytochemistry 51, 499-505. doi: 10.1016/S0031-9422(99)00031-X

Babu, R. C., Zhang, J., Blum, A., Ho, T-H. D., Wu, R., and Nguyen, H. T. (2004). HVA1, a LEA gene from barley confers dehydration tolerance in transgenic rice (Oryza sativa L.) via cell membrane protection. Plant Sci. 166, 855-862. doi: 10.1016/j.plantsci.2003.11.023

Bartels, D., and Hussain, S. S. (2011). "Resurrection plants: physiology and molecular biology," in Plant Desiccation Tolerance, eds U. Luttge, E. Beck, and D. Bartels (Berlin: Springer), 339-364.

Bartels, D., Schneider, K., Terstappen, G., Piatkowski, D., and Salamini, F. (1990). Molecular cloning of abscissic acid-modulated genes which are induced during desiccation of the resurrection plant Craterostigma plantagineum. Planta 181, 27-34. doi: 10.1007/BF00202321

Battaglia, M., Olvera-Carrillo, Y., Garciarrubio, A., Campos, F., and Covarrubias, A. A. (2008). The enigmatic LEA proteins and other hydrophilins. Plant Physiol. 148, 6-24. doi: 10.1104/pp.108.120725

Bayley, M., Petersen, S. O., Knigge, T., Köhler, H., and Holmstrup, M. (2001). Drought acclimation confers cold tolerance in the soil collembolan Folsomia candida. J. Insect Physiol. 47, 1197-1204. doi: 10.1016/S0022-1910(01)00104-4

Booker, F. L., and Miller, J. E. (1998). Phenylpropanoid metabolism and phenolic composition of soyabean (Glycine max L.) leaves following exposure to ozone. J. Exp. Bot. 49, 1191-1202. doi: 10.1093/jxb/49.324.1191

Boyko, A., and Kovalchuk, I. (2011). Genome instability and epigenetic modification: heritable responses to environmental stress? Curr. Opin. Plant Biol. 14, 260-266. doi: 10.1016/j.pbi.2011.03.003

Buitink, J., and Leprince, O. (2004). Glass formation in plant anhydrobiotes: survival in the dry state. Cryobiology 48, 215-228. doi: 10.1016/j.cryobiol.2004.02.011

Bruce, J. A. T., Matthes, C. M., Napier, A. J., and Pickett, A. J. (2007). Stressful "memories" of plants: evidence and possible mechanisms. Plant Sci. 173, 603-608. doi: 10.1016/j.plantsci.2007.09.002

Chinnusamy, V., and Zhu, J. (2009). Epigenetic regulation of stress responses in plants. Curr. Opin. Plant Biol. 12, 13. doi: 10.1016/j.pbi.2008.12.006

Cruz de Carvalho, M. H. (2008). Drought stress and reactive oxygen species: production, scavenging and signaling. Plant Signal. Behav. 3, 156-165. doi: 10.4161/psb.3.3.5536 
Daskalova, E., Dontcheva, S., Yahoubian, G., Minkov, I., and Toneva, V. (2011). A strategy for conservation and investigation of the protected resurrection plant Haberlea rhodopensis Friv. BioRisk 6, 41-60. doi: 10.3897/biorisk.6. 1568

Deng, X., Hu, Z., and Wang, H. (1999). mRNA differential display visualized by silver staining tested on gene expression in resurrection plant Boea hygrometrica. Plant Mol. Biol. Rep. 17, 1-7. doi: 10.1023/A:1007635714367

Deng, X., Hu, Z. A., Wang, H. X., Wen, X. G., and Kuang, T. Y. (2003). A comparison of photosynthetic apparatus of the detached leaves of the resurrection plant Boea hygrometrica with its non-tolerant relative Chirita heterotrichia in response to dehydration and rehydration. Plant Sci. 165, 851-861. doi: 10.1016/S0168-9452(03)00284-X

Deng, X., Phillips, J., Brautigam, A., Engstrom, P., Johannesson, H., Ou-werkerk, P. B., et al. (2006). A homeodomain leucine zipper gene from Craterostigma plantagineum regulates abscisic acid responsive gene expression and physiological responses. Plant Mol. Biol. 61, 469-489. doi: 10.1007/s11103-006-0023-x

de Oliveira, D. E., Seurinck, J., Inze, D., Montagu, M. V., and Botterman, J. (1990). Differential expression of five Arabidopsis genes encoding glycine-rich proteins. Plant Cell 2, 427-436. doi: 10.1105/tpc.2.5.427

De Pinto, M. C., and De Gara, L. (2004). Changes in the ascorbate metabolism of apoplastic and symplastic spaces are associated with cell differentiation. J. Exp. Bot. 55, 2559-2569. doi: 10.1093/jxb/erh253

Dinakar, C., Djilianov, D., and Bartels, D. (2012). Photosynthesis in desiccation tolerant plants: energy metabolism and antioxidative stress defense. Plant Sci. 182, 29-41. doi: 10.1016/j.plantsci.2011.01.018

Ding, Y., Fromm, M., and Avramova, Z. (2012). Multiple exposures to drought 'train' transcriptional responses in Arabidopsis. Nat. Commun. 3, 740. doi: 10.1038/ncomms 1732

Djilianov, D., Dobrev, P., Moyankova, D., Vankova, R., Georgieva, D., Gajdošová, S., et al. (2013). Dynamics of endogenous phytohormones during desiccation and recovery of the resurrection plant species Haberlea rhodopensis. J. Plant Growth Regul. 32, 564-574. doi: 10.1007/s00344-013-9323-y

Djilianov, D., Ivanov, S., Moyankova, D., Miteva, L., Kirova, E., Alexieva, V., et al. (2011). Sugar ratios, glutathione redox status and phenols in the resurrection species Haberlea rhodopensis and the closely related non-resurrection species Chirita eberhardtii. Plant Biol. 13, 767-776. doi: 10.1111/j.14388677.2010.00436.x

Doherty, C. J., Van Buskirk, H. A., Myers, S. J., and Thomashow, M. F. (2009). Roles for Arabidopsis CAMTA transcription factors in cold-regulated gene expression and freezing tolerance. Plant Cell 21, 972-984. doi: 10.1105/tpc.108.063958

Dubreuil, M., Riba, M., and Mayol, M. (2008). Genetic structure and diversity in Ramonda myconi (Gesneriaceae): effects of historical climate change on a preglacial relict species. Am. J. Bot. 95, 577-587. doi: 10.3732/ajb. 2007320

Dure, L., and Chalan, C. (1981). Developmental biochemistry of cotton seed embryogenesis and germination. XII. Purification and properties of principle storage protein. Plant Physiol. 68, 180-186. doi: 10.1104/pp.68.1.180

Dure, L., Crouch, M., J. Harada, J., Ho, T. H. D., Mundy, J., Quatrano, R., et al. (1989). Common amino acid sequence domains among the LEA proteins of higher plants. Plant Mol. Biol. 12, 475-486. doi: 10.1007/BF00036962

Farrant, J., Brandt, W., and Lidsey, G. G. (2007). An overview of mechanisms of desiccation tolerance in selected angiosperm resurrection plants. Plant Stress 1, 72-84.

Farrant, J. M., Lehne, A., Cooper, K., and Wiswedel, S. (2009). Desiccation tolerance in the vegetative tissues of the fern Mohria caffrorum is seasonally regulated. Plant J. 57, 65-79. doi: 10.1111/j.1365-313X.2008.03673.x

Farrant, J. M., and Moore, J. P. (2011). Programming desiccation-tolerance: from plants to seeds to resurrection plants. Curr. Opin. Plant Biol. 14, 340-345. doi 10.1016/j.pbi.2011.03.018

Farrant, J. M., Vander Willigen, C., Loffell, D. A., Bartsch, S., and Whittaker, A. (2003). An investigation into the role of light during desiccation of three angiosperm resurrection plants. Plant Cell Environ. 26, 1275-1286. doi: 10.1046/j.0016-8025.2003.01052.x

Furini, A., Koncz, C., Salamini, F., and Bartels, D. (1997). High level transcription of a member of a repeated gene family confers dehydration tolerance to callus tissue of Craterostigma plantagineum. EMBO J. 16, 3599-3608. doi: 10.1093/emboj/16.12.3599

Gaff, D., Bartels, D., and Gaff, J. L. (1997). Changes in gene expression during drying in a desiccation tolerant grass Sporobolus stapfianus and a desiccation sensitive grass Sporobolus pyramidalis. Aust. J. Plant Physiol. 24, 617-622. doi: 10.1071/PP96073

Gaff, D. F., and Loveys, B. R. (1984). Abscisic acid content and effects during dehydration of detached leaves of desiccation tolerant plants. J. Exp. Biol. 35, 1350-1358. doi: 10.1093/jxb/35.9.1350

Gaff, D. F., and Oliver, M. (2013). The evolution of desiccation tolerance in angiosperm plants: a rare yet common phenomenon. Funct. Plant Biol. 40, 315-328. doi: 10.1071/FP12321

Garrido, C., Paul, C., Seigneuric, R., and Kampinga, H. H. (2012). The small heat shock proteins family: the long forgotten chaperones. Int. J. Biochem. Cell Biol. 44, 1588-1592. doi: 10.1016/j.biocel.2012.02.022

Gechev, T. S., Dinakar, C., Benina, M., Toneva, V., and Bartels, D. (2012). Molecular mechanisms of desiccation tolerance in resurrection plants. Cell. Mol. Life Sci. 69, 3175-3186. doi: 10.1007/s00018-012-1088-0

Georgieva, K., Lenk, S., and Buschmann, C. (2008). Responses of the resurrection plant Haberlea rhodopensis to high irradiance. Photosynthetica 46, 208-215. doi: 10.1007/s11099-008-0034-8

Georgieva, K., Röding, A., and Büchel, C. (2009). Changes in some thylakoid membrane proteins and pigments upon desiccation of the resurrection plant. J. Plant Physiol. 166, 1520-1528. doi: 10.1016/j.jplph.2009.03.010

Georgieva, K., Sarvari, E., and Keresztes, A. (2010). Protection of thylakoids against combined light and drought by a luminal substance in the resurrection plant Haberlea rhodopensis. Ann. Bot. 105, 117-126. doi: 10.1093/aob/mcp 274

Georgieva, T., Christov, N., and Djilianov, D. (2012), Identification of desiccationregulated genes by cDNA-AFLP in Haberlea rhodopensis: a resurrection plant. Acta Physiol. Plant. 34, 1055-1066. doi: 10.1007/s11738-011-0902-x

Gutzat, R., and Scheid, O. M. (2012). Epigenetic responses to stress: triple defense? Curr. Opin. Plant Biol. 15, 568-573. doi: 10.1016/j.pbi.2012.08.007

He, F., Zhang, X., Hu, J. Y., Turck, F., Dong, X., Goebel, U., et al. (2012). Widespread interspecific divergence in cis-regulation of transposable elements in the Arabidopsis genus. Mol. Biol. Evol. 29, 1081-1091. doi: 10.1093/molbev/msr281

Hilbricht, T., Varotto, S., Sgaramella, V., Bartels, D., Salamini, F., and Furini, A. (2008). Retrotransposons and siRNA have a role in the evolution of desiccation tolerance leading to resurrection of the plant Craterostigma plantagineum. New Phytol. 179, 877-887. doi: 10.1111/j.1469-8137.2008.02480.x

Höfler, K., Migsch, H., and Rottenburg, W. (1941). Über die Austrocknungresistenz landwirtschaftlicherKulturpflanzen. Forschungsdienst. Organ Deut. Landwirtschaftswiss. 12, 50-61.

Holmstrup, M., Hedlund, K., and Boriss, H. (2002). Drought acclimation and lipid composition in Folsomia candida: implications for cold shock, heat shock and acute desiccation stress. J. Insect Physiol. 48, 961-970. doi: 10.1016/S00221910(02)00175-0

Huang, W., Yang, S. J., Zhang, S. B., Zhang, J. L., and Cao, K. F. (2012). Cyclic electron flow plays an important role in photoprotection for the resurrection plant Paraboea rufescens under drought stress. Planta 235, 819-828. doi: 10.1007/s00425-011-1544-3

Hundertmark, M., and Hincha, D. K. (2008). LEA (late embryogenesis abundant) proteins and their encoding genes in Arabidopsis thaliana. BMC Genomics 9:118 doi: $10.1186 / 1471-2164-9-118$

Ingram, J., and Bartels, D. (1996). The molecular basis of dehydration tolerance in plants. Annu. Rev. Plant Physiol. Plant Mol. Biol. 47, 377-403. doi: 10.1146/annurev.arplant.47.1.377

Ji, F., Li, N., and Deng, X. (2009). Calcium contents and high calcium adaptation of plants in karst area of China. Chin. J. Plant Ecol. 33, 926-935. doi: 10.3773/j.issn.1005-264x.2009.05.012

Jiang, G., Wang, Z., Shang, H., Yang, W., Hu, Z., Phillips, J., et al. (2007). Proteome analysis of leaves from the resurrection plant Boea hygrometrica in response to dehydration and rehydration. Planta 225, 1405-1420. doi: 10.1007/s00425-0060449-z

Jones, L., and McQueen-Mason, S. (2004). A role for expansins in dehydration and rehydration of the resurrection plant Craterostigma plantagineum. FEBS Lett. 559, 61-65. doi: 10.1016/S0014-5793(04)00023-7

Jovanovic, Z., Rakic, T., Stevanovic, B., and Rodovic, S. (2011). Characterization of oxidative and antioxidative events during dehydration and rehydration of resurrection plants Ramonda nathaliae. Plant Growth Regul. 64, 231-240. doi: 10.1007/s10725-011-9563-4

Kasuga, M., Liu, Q., Yamaguchi-Shinozaki, S. M. K., and Shinozaki, K. (1999). Improving plant drought, salt, and freezing tolerance by gene transfer of a 
single stress-inducible transcription factor. Nat. Biotechnol. 17, 287-291. doi: $10.1038 / 7036$

Kiew, R. (2009). The natural history of Malaysian Gesneriaceae. Malayan Nat. J. 61, 257-265.

Kim, J. M., To, K. T., Nishioka, T., and Seki, M. (2010). Chromatin regulation functions in plant abiotic stress responses. Plant Cell Environ. 33, 604-611. doi: 10.1111/j.1365-3040.2009.02076.x

Kirch, H. H., Nair, A., and Bartels, D. (2001). Novel ABA and dehydration inducible aldehyde dehydrogenase genes isolated from the resurrection plant Craterostigma plantagineum and Arabidopsis thaliana. Plant J. 28, 555-567. doi: 10.1046/j.1365 313X.2001.01176.x

Kouzarides, T. (2007). Chromatin modifications and their function. Cell 128, 693 705. doi: 10.1016/j.cell.2007.02.005

Kranner, I., and Birtic, S. (2005). A modulating role for antioxidants in desiccation tolerance. Integr. Comp. Biol. 45, 734-740. doi: 10.1093/icb/45.5.734

Liu, X., Wang, Z., Wang, L., Wu, R., Phillips, J., and Deng, X. (2009). LEA 4 group genes from the resurrection plant Boea hygrometrica confer dehydration tolerance in transgenic tobacco. Plant Sci. 176, 90-98. doi: 10.1016/j.plantsci.2008.09.012

Martinelli, T. (2008). In situ localization of glucose and sucrose in dehydrating leaves of Sporobolus stapfianus. J. Plant Physiol. 165, 580-587. doi 10.1016/j.jplph.2007.01.019

Mihailova, G., Petkova, S., Büchel, C., and Georgieva, K. (2011). Desiccation of the resurrection plant Haberlea rhodopensis at high temperature. Photosynth. Res. 108, 5-13. doi: 10.1007/s11120-011-9644-2

Mirouze, M., and Paszkowski, J. (2011). Epigenetic contribution to stress adaptation in plants. Curr. Opin. Plant Biol. 14, 267-274. doi: 10.1016/j.pbi.2011.03.004

Mishiba, K., Nagashima, Y., Suzuki, E., Hayashi, N., Ogata, Y., Shimada, Y., etal. (2013). Defects in IRE1 enhance cell death and fail to degrade mRNAs encoding secretory pathway proteins in the Arabidopsis unfolded protein response. Proc. Natl. Acad. Sci. U.S.A. 110, 5713-5718. doi: 10.1073/pnas.12190 47110

Mittler, R. (2002). Oxidative stress, antioxidants and stress tolerance. Trends Plant Sci. 7, 405-410. doi: 10.1016/S1360-1385(02)02312-9

Mittler, R., Vanderauwera, S., Gollery. M., and Van Breusegem, F. (2011). The reactive oxygen gene network of plants. Trends Plant Sci. 9, 490-498. doi: 10.1016/j.tplants.2004.08.009

Moore, J. P., Farrant, J. M., and Driouich, A. (2008). A role for pectin-associated arabinans in maintaining the flexibility of the plant cell wall during water deficit stress. Plant Signal. Behav. 3, 102-104. doi: 10.4161/psb.3.2.4959

Moore, J. P., Nguema-Ona, E., Chevalier, L., Lindsey, G. G., Brandt, W. F., Lerouge, P., et al. (2006). Response of the leaf cell wall to desiccation in the resurrection plant Myrothamnus flabellifolius. Plant Physiol. 141, 651-662. doi: 10.1104/pp.106.077701

Mousavi, A., and Hotta, Y. (2005). Glycine-rich proteins: a class of novel proteins. Appl. Biochem. Biotechnol. 120, 169-174. doi: 10.1385/ABAB:120:3:169

Mowla, S. B., Thomson, J. A., Farran, J. M., and Mundree, S. G. (2002) A novel stress-inducible antioxidant enzyme identified from the resurrection plant Xerophyta viscosa Baker. Planta 215, 716-726. doi: 10.1007/s00425-0020819-0

Müller, J., Sprenger, N., Bortlik, K., Boller, T., and Wiemken, A. (1997). Desiccation increases sucrose levels in Ramonda and Haberlea, two genera of resurrection plants in the Gesneriaceae. Physiol. Plant. 100, 153-158. doi: 10.1111/j.13993054.1997.tb03466.x

Neale, A. D., Blomstedt, C. K., Bronson, P., Le, T-N., Guthridge, K., Evans, J., et al. (2000). The isolation of genes from the resurrection grass Sporobolus stapfians during severe drought stress. Plant Cell Environ. 23, 265-278. doi: 10.1046/j.13653040.2000.00548.x

Nishizawa, A., Yabuta, Y., and Shigeoka, S. (2008). Galactinol and raffinose constitute a novel function to protect plants from oxidative damage. Plant Physiol. 147, 1251-1263. doi: 10.1104/pp.108.122465

Norwood, M., Toldi, O., Richter, A., and Scott, P. (2003). Investigation into the ability of roots of the poikilohydric plant Craterostigma plantagineum to survive dehydration stress. J. Exp. Bot. 54, 2313-2321. doi: 10.1093/jxb/ erg255

Norwood, M., Truesdale, M. R., Richter, A., and Scott, P. (2000). Photosynthetic carbohydrate metabolism in the resurrection plant Craterostigma plantagineum. J. Exp. Bot. 51, 159-165. doi: 10.1093/jexbot/51.343.159
Noctor, G., and Foyer, C. H. (1998). Ascorbate and glutathione: keeping active oxygen under control. Annu. Rev. Plant Biol. 49, 249-279. doi: 10.1146/annurev.arplant.49.1.249

Oliver, M. J., Guo, L., Alexander, D. C., Ryals, J. A., Wone, B. W., and Cushman, J. C. (2011). A sister group contrast using untargeted global metabolomic analysis delineates the biochemical regulation underlying desiccation tolerance in Sporobolus stapfianus. Plant Cell 23, 1231-1248. doi: 10.1105/tpc.110.082800

Oliver, M. J., Tuba, Z., and Mishler, B. D. (2000). The evolution of vegetative desiccation tolerance in land plants. Plant Ecol. 151, 85-100. doi: 10.1023/A:1026550808557

Pang, C. H., and Wang, B. S. (2008). “Oxidative stress and salt tolerance in plants”, in Progress in Botany, eds U. Luttge, W. Beyschlag, and J. Murata (Berlin: Springer), 231-245.

Park, B. J., Liu, Z. C., Kanno, A., and Kameya, T. (2005). Genetic improvement of Chinese cabbage for salt and drought tolerance by constitutive expression of a $B$. napus LEA gene. Plant Sci. 169, 553-558. doi: 10.1016/j.plantsci.2005.05.008

Peters, S., Mundree, S. G., Thomson, J. A., Farrant, J. M., and Keller, F. (2007). Protection mechanisms in the resurrection plant Xerophyta viscosa (Baker): both sucrose and raffinose family oligosaccharides (RFOs) accumulate in leaves in response to water deficit. J. Exp. Bot. 58, 1947-1956. doi: 10.1093/jxb/erm056

Petrova, G., Dzhambazova, T., Moyankova, D., Georgieva, D., Michova, A., Djilianov, D., et al. (2013). Morphological variation, genetic diversity and genome size of critically endangered Haberlea (Gesneriaceae) populations in Bulgaria do not support the recognition of two different species. Plant Syst. Evol. doi: 10.1007/s00606-013-0857-z

Phillips, J. R., Hilbricht, T., Salamini, F., and Bartels, D. (2002). A novel abscisic acid- and dehydration-responsive gene family from the resurrection plant Craterostigma plantagineum encodes a plastid-targeted protein with DNA-binding activity. Planta 215, 258-266. doi: 10.1007/s00425-002-0755-z

Piatkowski, D., Schneider, K., Salamini, F., and Bartels, D. (1990). Characterization of five abscisic acid-responsive cDNA clones isolated from the desiccation tolerant plant Craterostigma plantagineum and their relationship to other water stress genes. Plant Physiol. 94, 1682-1688. doi: 10.1104/pp.94.4.1682

Picó, F. X., and Riba, M. (2002). Regional-scale demography of Ramonda myconi: remnant population dynamics in a preglacial relict species. Plant Ecol. 161, 1-13. doi: 10.1023/A:1020310609348

Piegu, B., Guyot, R., Picault, N., Roulin, A., Saniyal, A., Kim, H., et al. (2006). Doubling genome size without polyploidization: dynamics of retrotranspositiondriven genomic expansions in Oryza australiensis, a wild relative of rice. Genome Res. 16, 1262-1269. doi: 10.1101/gr.5290206

Porembski, S. (2011). "Evolution, diversity and habitats of poikilohydrous plants," in Plant Tolerant Desiccation, eds U. Luttge, E. Beck, and D. Bartels (Berlin: Springer), 139-156.

Rakić, T., Quartacci, M. F., Cardelli, R., Navari-Izzo, F., and Stevanović, B. (2009). Soil properties and their effect on water and mineral status of resurrection Ramonda serbica. Plant Ecol. 203, 13-21. doi: 10.1007/s11258-008-9498-7

Rigal, M., and Mathieu, O. (2011). A "mille-feuille" of silencing: epigenetic control of transposable elements. Biochim. Biophys. Acta 1809, 452-458. doi: 10.1016/j.bbagrm.2011.04.001

Sachetto-Martins, G., Franco, L. O., and de Oliveira, D. E. (2000). Plant glycine-rich proteins: a family or just proteins with a common motif? Biochim. Biophys. Acta 492, 1-14.

Sgherri, C., Stevanovic, B., and Navari-Izzo, F. (2004). Role of phenolics in the antioxidative status of the resurrection plant Ramonda serbica during dehydration and rehydration. Physiol. Plant. 122, 478-485. doi: 10.1111/j.13993054.2004.00428.x

Shao, H., Liang, Z., and Shao, M. (2005). LEA proteins in higher plants: structure, function, gene expression and regulation. Colloids Surf. B Biointerfaces 45, 131135. doi: 10.1016/j.colsurfb.2005.07.017

Sherwin, H. W. (1995). Desiccation Tolerance and Sensitivity of Vegetative Plant Tissue. PhD thesis, University of Natal, Durban, South Africa.

Sherwin, H. W., and Farrant, J. M. (1998). Protection mechanisms against excess light in the resurrection plants Craterostigma wilmsii and Xerophyta viscosa. Plant Growth Regul. 24, 203-210. doi: 10.1023/A:1005801610891

Smith-Espinoza, C. J., Phillips, J. R., Salamini, F., and Bartels, D. (2005). Identification of further Craterostigma plantagineum cdt mutants affected in abscisic acid mediated desiccation tolerance. Mol. Genet. Genomics 274, 364-372. doi: 10.1007/s00438-005-0027-2 
Sokol, A., Kwiatkowska, A., Jerzmanowski, A., and Prymakowska-Bosak, M. (2007). Up-regulation of stress-inducible genes in tobacco and Arabidopsis cells in response to abiotic stresses and ABA treatment correlates with dynamic changes in histone $\mathrm{H} 3$ and $\mathrm{H} 4$ modifications. Planta 227, 245-254. doi: 10.1007/s00425-007-0612-1

Song, W. Y., Choi, K. S., Alexis, D., Martinoia, E., and Lee, Y. (2011). Brassica juncea plant cadmium resistance 1 protein (BjPCR1) facilitates the radial transport of calcium in the root. Proc. Natl. Acad. Sci. U.S.A. 108, 19808-19813. doi: 10.1073/pnas.1104905108

Thomashow, M. F. (2010). Molecular basis of plant cold acclimation: insights gained from studying the CBF cold response pathway. Plant Physiol. 154, 571-577. doi: 10.1104/pp.110.161794

Toby, J. A. B., Michaela, C. M., Johnathan, A. N., and John, A. P. (2007). Stressful "memories" of plants: evidence and possible mechanisms. Plant Sci. 173, 603-608. doi: 10.1016/j.plantsci.2007.09.002

Tunnacliffe, A., and Wise, M. J. (2007). The continuing conundrum of the LEA proteins. Naturwissenschaften 94, 791-812. doi: 10.1007/s00114-007-0254-y

Venner, S., Feschotte, C., and Biémont, C. (2009). Dynamics of transposable elements: towards a community ecology of the genome. Trends Plant Sci. 25, 317-323.

Vicré, M., Farrant, J. M., and Driouich, A. (2004a). Insights into the cellular mechanisms of desiccation tolerance among angiosperm resurrection plant species. Plant Cell Environ. 27, 1365-3040. doi: 10.1111/j.1365-3040.2004.01212.x

Vicré, M., Lerouxel, O., Farrant, J., Lerouge, P., and Driouich, A. (2004b). Composition and desiccation-induced alterations of the cell wall in the resurrection plant Craterostigma wilmsii. Physiol. Plant. 120, 229-239. doi: 10.1111/j.0031-9317.2004.0234.x

Wang, L., Shang, H., Liu, Y., Zheng, M., Wu, R., Phillips, J., et al. (2009a). A role for a cell wall localized glycine-rich protein in dehydration and rehydration of the resurrection plant Boea hygrometrica. Plant Biol. 11, 837-848. doi 10.1111/j.1438-8677.2008.00187.x

Wang, Z., Zhu, Y., Wang, L., Liu, X., Liu, Y., Phillips, J., et al. (2009b). A WRKY transcription factor participates in dehydration tolerance in Boea hygrometrica by binding to the W-box elements of the galactinol synthase (BhGolS1) promoter. Planta 230, 1155-1166. doi: 10.1007/s00425-009-1014-3

Wang, Z., Liu, Y., Wei, J., and Deng, X. (2012). Cloning and expression of a gene encoding a raffinose synthase in the resurrection plant Boea hygrometrica. Bull. Bot. 47, 44-54. doi: 10.3724/SP.J.1259.2012.00044

White, P. J., and Broadley, M. R. (2003). Calcium in plants. Ann. Bot. 92, 487-511. doi: $10.1093 / \mathrm{aob} / \mathrm{mcg} 164$

Wu, H., Shen, Y., Hu, Y., Tan, S., and Lin, Z. (2011). A phytocyaninrelated early nodulin-like gene, $\mathrm{BcBCP} 1$, cloned from Boea crassifolia enhances osmotic tolerance in transgenic tobacco. J. Plant Physiol. 168, 935-943. doi: 10.1016/j.jplph.2010.09.019
Wu, R. H., Wang, L. L., Wang, Z., Shang, H. H., Liu, X., Zhu, Y., et al. (2009) Cloning and expression analysis of a dirigent protein gene from the resurrection plant Boea hygrometrica. Prog. Nat. Sci. 19, 347-353. doi: 10.1016/j.pnsc.2008. 07.010

Xu, D. P., Duan, X. L., Wang, B. Y., Hong, B. M., Ho, T. H., and Wu, R. (1996). Expression of a late embryogenesis abundant protein gene, HVA1, from barley confers tolerance to water deficit and salt stress in transgenic rice. Plant Physiol. 110, 249-257.

Zhang, H. M., and Zhu, J. K. (2011). RNA-directed DNA methylation. Curr. Opin. Plant Biol. 14, 142-147. doi: 10.1016/j.pbi.2011.02.003

Zhang, L., Ji, F., Wang, L., Qi, D., Zhu, Y., and Deng, X. (2012). A small C2-domain protein from the resurrection plant Boea hygrometrica promotes plant responses to abscisic acid. Bull. Bot. 47, 11-27. doi: 10.3724/SP.J.1259.2012.00011

Zhang, T., Fang, Y., Wang, X., Deng, X., Zhang, X., Hu, S., et al. (2011). The complete chloroplast and mitochondrial genome sequences of Boea hygrometrica: insights into the evolution of plant organellar genomes. PLoS ONE 7:e30531. doi: 10.1371/journal.pone.0030531

Zhang, Z., Wang, B., Sun, S., and Deng, X. (2013). Molecular cloning and differential expression of sHSP gene family members from the resurrection plant Boea hygrometrica in response to abiotic stresses. Biologia 68, 651-661. doi: 10.2478/s11756-013-0204-4

Zhu, Y., Wang, Z., Jing, Y. J., Wang, L. L., Liu, X., Liu, Y. X., et al. (2009). Ectopic over-expression of BhHsfl, a heat shock factor from the resurrection plant Boea hygrometrica, leads to increased thermotolerance and retarded growth in transgenic Arabidopsis and tobacco. Plant Mol. Biol. 71, 451-467. doi: $10.1007 /$ s11103-009-9538-2

Conflict of Interest Statement: The authors declare that the research was conducted in the absence of any commercial or financial relationships that could be construed as a potential conflict of interest.

Received: 30 August 2013; accepted: 17 October 2013; published online: 12 November 2013.

Citation: Mitra J, Xu G, Wang B, Li M and Deng X (2013) Understanding desiccation tolerance using the resurrection plant Boea hygrometrica as a model system. Front. Plant Sci. 4:446. doi: 10.3389/fpls.2013.00446

This article was submitted to Plant Physiology, a section of the journal Frontiers in Plant Science.

Copyright (c) 2013 Mitra, Xu, Wang, Li and Deng. This is an open-access article distributed under the terms of the Creative Commons Attribution License (CC BY). The use, distribution or reproduction in other forums is permitted, provided the original author(s) or licensor are credited and that the original publication in this journal is cited, in accordance with accepted academic practice. No use, distribution or reproduction is permitted which does not comply with these terms. 